\title{
Information Exchange, Market Transparency and Dynamic Oligopoly
}

\author{
Overgaard, Per Baltzer; Møllgaard, H. Peter
}

Document Version

Final published version

Publication date:

2005

License

CC BY-NC-ND

Citation for published version (APA):

Overgaard, P. B., \& Møllgaard, H. P. (2005). Information Exchange, Market Transparency and Dynamic Oligopoly. Copenhagen Business School, CBS. Working Paper / Department of Economics. Copenhagen Business School No. 13-2005

Link to publication in CBS Research Portal

\section{General rights}

Copyright and moral rights for the publications made accessible in the public portal are retained by the authors and/or other copyright owners and it is a condition of accessing publications that users recognise and abide by the legal requirements associated with these rights.

Take down policy

If you believe that this document breaches copyright please contact us (research.lib@cbs.dk) providing details, and we will remove access to the work immediately and investigate your claim.

Download date: 26. Apr. 2023 
Copenhagen

Business School

HANDFISHOISKOIFN

\section{Department of Economics}

Copenhagen Business School

Working paper 13-2005

INFORMATION EXCHANGE, MARKET TRANSPARENCY AND DYNAMIC OLIGOPOLY

Per Baltzer Overgaard H.Peter Møllgaard 


\title{
Information Exchange, Market Transparency and Dynamic Oligopoly*
}

\author{
Per Baltzer Overgaard \\ School of Economics and Management, University of Aarhus, Denmark, www.econ.au.dk, \\ Copenhagen Economics ApS, www.copenhageneconomics.com, \\ and Centre for Industrial Economics, www.econ.ku.dk/cie/ \\ povergaard@econ.au.dk \\ H. Peter Møllgaard \\ Department of Economics, Copenhagen Business School, Denmark, uk.cbs.dk/econ/, \\ Copenhagen Economics ApS, www.copenhageneconomics.com, \\ and Centre for Industrial Economics, www.econ.ku.dk/cie/ \\ hpm.eco@cbs.dk
}

November 2005

\begin{abstract}
In the economics literature, various views on the likely (efficiency) effects of information exchange, communication between firms and market transparency present themselves. Often these views on information flows are highly conflicting. On the one hand, it is argued that increased information dissemination improves firm planning to the benefit of society (including customers) and/or allows potential customers to make the right decisions given their preferences. On the other hand, the literature also suggests that increased information dissemination can have significant coordinating or collusive potential to the benefit of firms but at the expense of society at large (mainly, potential customers). In this chapter, we try to make sense of these views, with the aim of presenting some simple lessons for antitrust practice. In addition, the chapter presents some cases, from both sides of the Atlantic, where informational issues have played a significant role.
\end{abstract}

*Prepared for Wayne Dale Collins (ed.), Issues in Competition Law and Policy, (forthcoming) American Bar Association. We wish to thank Christopher Wilson, Centre for Competition Policy, University of East Anglia for comments on an earlier draft. 


\section{Contents}

1 Introduction and Motivation $\quad 3$

2 A Primer on Information in Static Oligopoly 4

3 A Canonical Model of Dynamic Oligopoly Competition 6

3.1 Information flows between firms . . . . . . . . . . . . . . . . . . . 10

3.1 .1 Detection lags . . . . . . . . . . . . . . . . . . . . . 10

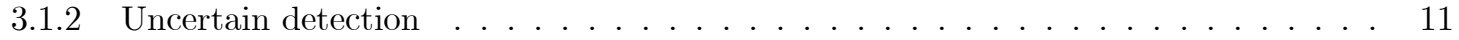

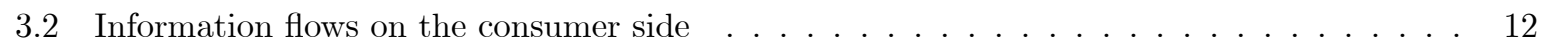

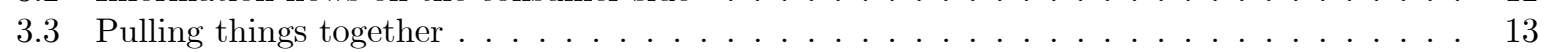

4 Lessons for Antitrust $\quad 15$

5 Representative Cases $\quad 18$

5.1 A Concrete Case . . . . . . . . . . . . . . . . . . . . . . 18

5.2 Cheap Talk in the Air and on the Ground . . . . . . . . . . . . . . . . . . 20

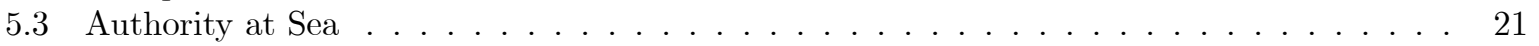

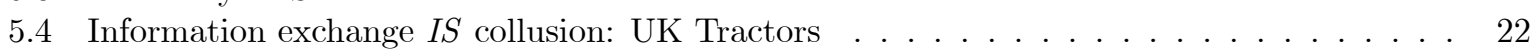

6 Final Remarks 23 


\section{Introduction and Motivation}

Antitrust policy and consumer protection tend to take somewhat different attitudes to information dissemination and market transparency. Briefly, antitrust law and practice in most jurisdictions focus on the potential coordinating/collusive effects of a liberal flow of information between firms, and, as a consequence, take a dim view of such flows. In contrast, consumer agencies focus on the ability of consumers to do comparison shopping, and, thus, insist that easy access to information on prices and product characteristics is a sine qua non of intensive inter-firm competition. Despite the fact that the references made to information flows may relate to the flow of different pieces of information and/or to the flow between different groups of economic decision makers, it seems clear that there is a potential conflict between these views. In the following, we shall try to make sense of these views with reference to both economic theory and various case material. In the process, we pull out some conclusions for antitrust policy.

Before we continue, let us add a word of caution. Whatever the view on information dissemination and market transparency in a specific case may be, both antitrust and consumer protection in market economies must fundamentally be based on the presumption that markets work, if they are allowed to. In mainstream economics this can, of course, be traced to the invisible hand of Smith (1776) and, possibly, even further. As regards the information requirements of optimal (or, at least, sound) economic decision making, the economy of the price system (as opposed to a planning-and-command system) was explained by Hayek (1945). Hence, for markets to work, the price system must aggregate the dispersed information on consumer wants and the fundamental scarcity of resources. It follows that generally opaque prices, hidden discounts, etc., might cause problems for the efficient functioning of markets. Thus, whatever reservations are expressed below on the competitive (or, efficiency) effects of information dissemination should not be taken too far. The main point of the modelling and discussion to follow is to suggest that under certain (identifiable) circumstances, the effects of certain kinds of information dissemination and communication between economic agents may be ambiguous or even malign from the perspective of competition and efficiency of resource allocation. In particular, we shall suggest that changing the flow information may be a two-edged sword particularly in those market conditions with which antitrust is most concerned: concentrated oligopoly.

First, to make sense of the two views outlined in the first paragraph, it is important to note the somewhat different temporal perspectives underlying the arguments. Antitrust practitioners seem to have a dynamic model of oligopoly coordination between suppliers of substitutes in mind. In such a model, it is relatively well-established in the economics literature (see e.g. Stigler (1964), Tirole (1989, ch. 6), Kühn (2001) or Møllgaard \& Overgaard (2001)) that horizontal coordination/collusion (whether tacit or explicit) is made difficult - if not impossible - if firms compete under a veil of ignorance concerning the actions of rivals. Hence, oligopolistic firms will have a common interest in improving the information flows between themselves. Speedy access to accurate information about the individual past transactions and future intentions of rivals will generally have a strong coordinating potential. Therefore, business history is replete with examples of rival oligopolists setting up various institutions (legal as well as clandestine) with a view to exchanging strategically sensitive, firm-specific information.

Proponents of the consumer interest tend to take a more static perspective. On the assumption (heroic as it may sometimes be) that competing firms are fully informed about each others strategies, the purpose of enabling a more liberal flow of information is largely to benefit weak consumers/potential customers and, possibly, potential entrants. Presently, the motivating example is almost invariably a reference to online shop-bots. Shop-bots allow potential customers to compare a multitude of different market offerings by pressing a few keys (thus, at low cost). This allows customers to shop around easily, turning competition between suppliers of close substitutes into something akin to intensive Bertrand-style competition. Consequently, proponents of this view have not only suggested that information should be allowed to flow freely, but even that the gathering, processing and dissemination of the information to potential customers should be subsidised by the public purse or by levying a duty on firms to foot the bill. Thus, government-sponsored and/or -funded information-transmission mechanisms have been set 
up.

Secondly, it should be noticed that the information referred to under the different views above may not be the same. Antitrust practitioners refer largely to the exchange of information - such as prices (past, present or future), meet-or-beat competition clauses, quantities, capacities, buyer identities, investment plans, etc. - between firms to the possible exclusion of potential customers and entrants, whereas consumer groups and agencies refer to information - such as prices, product characteristics, warranty terms, etc. flowing from firms to potential customers and entrants, that is, to the public. So, properly interpreted, it is entirely possible that the "antitrust view" and the "consumer view" may both be on the right track, but in different dimensions.

This, of course, suggests that for practical antitrust, which encompasses a general efficiency concern embodying both firm and consumer interests, it is very important that attention be paid to the detailed features and effects of the information exchanged: is the information exchanged kept proprietary by existing firms, or does it flow to the public (potential customers and entrants)? when do the different parties gain access to the information exchanged? absent the information exchange, who has access to which pieces of information? does the information exchanged relate to the past, the present or to future intentions? can the information exchanged subsequently be retracted or revised? if the information exchanged relates to future intentions, does it commit firms vis á vis potential customers?

The outline of this chapter is as follows. The next section briefly summarizes some analyses and views from economics of the role of information in static oligopoly. In Section 3 we outline a canonical model of dynamic oligopoly competition, which is flexible enough to illustrate the main theoretical points we wish to make related to information dissemination in a semi-formal, yet, readily intelligible, manner. Then, Section 4 pulls out some relatively general lessons for antitrust, while Section 5 briefly presents some cases from both sides of the Atlantic, in which information transmission and communication have played a central role. Finally, Section 6 contains a few concluding remarks.

\section{A Primer on Information in Static Oligopoly}

Before turning our attention to a more systematic account of the role of information in dynamic oligopoly competition, let us briefly remark on some general tenets of the economics literature relating mainly to the role of information in static analyses. The point of departure in economics is almost invariably a reference to the perfectly competitive ideal, against which different forms of actual competition in measured. The perfectly competitive ideal is predicated on a series of assumptions: the existence of many actual competitors, absense of entry barriers, free access to identical technologies, homogenous goods and perfectly informed agents. Although not always stated very explicitly, the latter refers to some free availability of perfect price information to existing firms, potential customers and potential entrants. Formally, for competition to play out according to this ideal, the point must be that there is some welldefined and commonly known way of producing the homogenous good in a cost minimizing way, which drives prices to this cost minimum. Heuristically, if some prices differ from this cost minimum, then consumers costlessly shopping around and/or entry and exit will quickly realign prices and minimum average costs. Thus, we could say that the functioning of the invisible hand (Smith, 1776) requires the information aggregated in the system of prices (Hayek, 1945). But note that the price information is mainly required by potential customers and entrants for competition to work. This would seem to suggest that the availability of information is key to understanding the likely intensity of competition in actual markets, the central theme of this chapter. Specifically, we could pose the following question: under imperfect competition, is it always good - in terms of intensified competition - to improve the flow of information on both sides of a market?

Pure competition 
Stiglitz (1989) maintains the assumptions of the perfectly competitive ideal except for the informational assumptions: potential customers are imperfectly informed about the prices quoted by different outlets (suppliers), and there are strictly positive search costs associated with obtaining accurate price information. ${ }^{1}$ The most basic modelling of this assumes that one group of consumers is perfectly informed of the prices at different outlets, while another group is initially imperfectly informed and must conduct search to discover prices. This may lead to several interesting market phenomena, such as absence of (pure strategy) equilibria or market breakdown, ${ }^{2}$ equilibrium prices significantly in excess of unit costs, prices which are non-decreasing in the number of suppliers and equilibria with price dispersion (for homogenous goods). All these phenomena represent fundamental departures from the equilibrium associated with perfect competition and, thus, illustrate the importance of the assumption of full information on the part of potential customers. With missing price information and significant search costs, some consumers are locked into particular suppliers (they are said to be captive). On the one hand, this explains that prices can be dispersed and exceed unit costs, and, on the other, that an increase in the number of firms does not (necessarily) lead to intensified price competition. ${ }^{3}$ It follows from models of this type that if only consumer search costs can be brought down significantly, through, e.g., the introduction of free and effective search engines and shop-bots to accompany the spread of online trading and/or the establishment of specialized price-comparison sites on the internet, then consumer prices can be brought down significantly. This line of argument might explain the lobbying of consumer groups for the facilitation (and public subsidization) of price comparisons relating to credit and insurance products. Indeed, this has led some commentators ${ }^{4}$ to hail the digital market place as the coming of the perfectly competitive ideal making regulation and antitrust redundant. ${ }^{5}$

\section{Static oligopoly}

As we shall see more fully in the next section, the evaluation of the effects of information dissemination on competition is complicated further, if we also drop the assumption of many suppliers and turn to oligopoly instead. First of all, in the oligopoly setting, it is important to make a distinction between information flowing on the firm side and on the consumer side of a given market. Secondly, as suggested already in the Introduction, the time horizon plays a crucial role.

Turning first, though, to the static oligopoly case, Kühn \& Vives $(1995)^{6}$ were the first to systematically assess the incentives of firms to share information on key variables such as demands and costs as well as the welfare implications of information sharing between firms, when firms compete non-cooperatively by setting e.g. prices or quantities/capacities. As far as clear antitrust implications are concerned, Kühn \& Vives are skeptic, since specific modelling details are key to assessing whether firms have an incentive to share initially dispersed information, and whether information sharing have positive or negative welfare implications. Heuristically, firm incentives to share information trade off the privately beneficial effects for firms related to improved precision of planning against the (possibly) negative strategic (competition) effects of sharing information with rivals. The welfare implications of information sharing between firms, in turn, depend on both the nature of competition (Cournot quantity-competition vs. Bertrand

\footnotetext{
${ }^{1}$ For a seminal study of the role of consumer search costs, see Stigler (1961).

${ }^{2}$ The market breakdown is similar to that potentially arising in Akerlof's (1970) lemons model, where good-quality products (peaches) are priced out of the market by poor-quality products (lemons), due to the inability of potential customers to verify quality of individual items before purchase.

${ }^{3}$ An increased number of firms may imply that a given consumer will have to conduct a larger (expected) number of costly searches before a low price is found, and this dampens the consumer incentive to search. This, in turn, implies that even with a substantial number of firms, no single firm firm may have an incentive to lower price.

${ }^{4}$ No one mentioned, no one forgotten.

${ }^{5}$ See Shapiro \& Varian (1999) for a rather critical assessment of this point of view. More detailed accounts of the challenges to antitrust in the online economy can be found in FTC (2000) and Frontier Economics (2000). A brief account can be found in Møllgaard \& Overgaard (2001), who focus on dynamic issues to which we return below.

${ }^{6}$ For more recent presentations of the subject matter, builiding in large part on Kühn \& Vives, see e.g. Kühn (2001), Vives (2002), OECD (2001) and Nitsche \& von Hinten-Reed (2004). A detailed account is beyond the scope of this paper, and the following is just meant to convey the flavor of some key results.
} 
price-competition) and on the nature of the initially dispersed information (stochastic shocks with predominantly common components or shocks with predominantly private, firm-specific components). Even though Kühn \& Vives (1995) are able to generate relatively clear and unambiguous analytical results for any given model specification, ${ }^{7}$ these are not results which are immediately operative from the perspective of practical antitrust given the limited information available to antitrust agencies.

Agency problems and adverse selection

Finally, let us comment briefly on a couple of issues related to cases where firms or their executives are, initially, at an informational disadvantage vis a vis either potential customers or employees. ${ }^{8}$

It should be fairly evident that absent competition concerns, individual firm performance (cost minimization) in a stochastic environment may sometimes improve significantly, if employee performance contracts can be tied to a richer set of information than that arising purely from within the organization. Relative perfomance evaluation and benchmarking requires information relating to firms in similar circumstances, which typically would include the most immediate rivals. Thus, inter-firm sharing of sales and cost data may, potentially, be efficiency-enhancing. However, exchange of detailed, firm-specific information among rivals also has significant coordinating potential, as we shall explore below. More aggregated industry data may be sufficient from the efficient contracting perspective, while having less coordinating potential. Aggregate data is certainly sufficient for benchmarking against some industry average.

Similarly, firms in oligopolistic industries sometimes find themselves in a situation where they, initially, lack some relevant information about the chracteristics of their potential customers. For example, in the credit and insurance industries, customers may shop around between a limited number of providers. Without inter-firm information exchange, firms may have relatively limited information about the past payment or accident records of individual, new customers. This asymmetry of information may lead to severe adverse selection problems, resulting in inefficient market outcomes; inefficiencies which are unrelated to the oligopolistic nature of the industries. In such a setting, inter-firm exchange of information (in the form of individual customer records) may well be efficiency-enhancing.

\section{A Canonical Model of Dynamic Oligopoly Competition}

The general aim of this section is to illustrate how different notions of information exchange, communication and market transparency (and changes thereof) ultimately relate to competition and market efficiency from a dynamic perspective. We propose to do so by introducing an abstract, canonical model, which first serves as a benchmark for capturing the essential differences between static and dynamic oligopoly competition as viewed by economists. The model is canonical in the sense that it is largely void of institutional detail and functional form assumptions relating to demand and costs. At the same time, it is flexible enough to allow us to subsequently introduce various assumptions about information flows on both the supply side (that is, between firms) and the demand side (that is, between consumers or potential customers) of the relevant market in question. The latter feature, of course, is what enables us to make some comments of relevance for antitrust practice without relying (too much) on specific modelling details.

\section{The canonical model}

Consider a symmetric oligopoly. ${ }^{9}$ Firms meet every period in some market place and simultaneously choose their strategies for that period. ${ }^{10}$ The strategic interaction unfolding in a given period is referred to as a stage-game. Suppose that this stage-game has a unique socalled Nash Equilibrium profile with

\footnotetext{
${ }^{7}$ That is, within the class of models considered.

${ }^{8}$ The following remarks are based on the more detailed account in Kühn (2001).

${ }^{9}$ That is, some market with at least two but a relatively limited number of identical firms. The symmetry assumption made throughout is largely for expositional convenience.

${ }^{10}$ For now, the exact nature of the strategies is unimportant, but well known models of price or quantity setting behavior
} 
associated (symmetric) profits $\pi^{N}$ to each firm. ${ }^{11}$ Alternatively, if the firms were somehow able to collude perfectly in their simultaneous choice of strategies, then we assume that profits to each firm would be $\pi^{C}$. Naturally, we would expect that $\pi^{C}>\pi^{N}$. However, on the assumption that the collusive outcome does not coincide with the Nash Equilibrium outcome, then each firm would have a basic incentive to deviate from (tacit or explicit) collusion. Hence, if all the rivals of a given firm play the collusive strategy in the stage game (assumed unique), there is a best response (best deviation) of this firm giving rise to one-shot payoffs of $\pi^{D}$ for that firm, where $\pi^{D}>\pi^{C}$. Hence, we have that $\pi^{D}>\pi^{C}>\pi^{N}$.

Thus, this set up captures that non-coordinated equilibrium profits, $\pi^{N}$, are lower than the profits firms could potentially attain, if they managed to collude, $\pi^{C}$. However, in the purely static setting, the collusive strategy profile ${ }^{12}$ giving rise to $\pi^{C}$ would be destabilized by profit-seeking individual firms striving to attain an even higher profit, $\pi^{D}$.

However, in a dynamic setting, things may be very different, in the sense that firms have access to a richer set of strategies. ${ }^{13}$ With the notation above, and on the additional assumption that the firms are restricted to socalled Nash trigger-strategies in the repeated game, ${ }^{14}$ the main point can be stated as follows: Following a collusive path ${ }^{15}$ gives rise to a constant cash flow/profit of $\pi^{C}$, and the discounted payoffs of a given firm are

$$
V^{C}=\pi^{C}+\delta \pi^{C}+\delta^{2} \pi^{C}+\delta^{3} \pi^{C} \ldots=\frac{1}{1-\delta} \pi^{C}=\pi^{C}+\frac{\delta}{1-\delta} \pi^{C}
$$

In contrast, deviating ${ }^{16}$ gives rise to the deviation profit, $\pi^{D}$, once followed by a string of non-collusive profits, $\pi^{N}$, starting next period. The associated discounted payoffs are

$$
V^{D}=\pi^{D}+\delta \pi^{N}+\delta^{2} \pi^{N}+\delta^{3} \pi^{N}+\ldots=\pi^{D}+\frac{\delta}{1-\delta} \pi^{N}
$$

where $\delta$ is some number between 0 and 1 capturing the (common) discount factor of the firms. ${ }^{17}$ Heuristically, the Nash trigger-strategies prescribe that firms start out by taking the collusive action and continue to do so as long as all firms have taken the collusive action in the past. If a single firm ever strays from the collusive path, all firms revert to the static equilibrium strategy from then on no matter what (that is, from the period following a deviation and forever after). The sustainability of perfect collusion in every period, thus, requires

or

$$
V^{C}=\pi^{C}+\frac{\delta}{1-\delta} \pi^{C} \geq \pi^{D}+\frac{\delta}{1-\delta} \pi^{N}=V^{D}
$$

$$
\frac{\delta}{1-\delta}\left(\pi^{C}-\pi^{N}\right) \geq \pi^{D}-\pi^{C}
$$

spring to mind. More generally, firms might be competing in promotional strategies (marketing and advertising), investments in production capacities, R\&D intensities, product characteristics, etc. Subsequently, we shall refer to the dynamic oligopoly competition as a repeated game, which implies that some of these model interpretations seem more natural than others.

${ }^{11}$ These Nash Equilibrium profits might also be referred to as $n$ on-cooperative, $n$ on-coordinated or $n$ on-collusive. Either way, below these are referred to by the superscript $N$.

${ }^{12}$ Viz. market sharing or monopoly pricing.

${ }^{13}$ These are socalled contingent strategies, where the action of a given firm in a given period may depend on the complete history of the dynamic interaction between the firms. For example, the price set by a given firm today may depend on the sequence of vectors of prices charged by rivals in the past. Thus, a firm can reward friendly behavior in the past by friendly behavior today and punish aggressive behavior in the past by aggressive behavior today.

${ }^{14}$ For analyses of even richer strategy spaces in oligopoly, see e.g. Abreu (1986), Lambertini \& Sasaki (1999) and Møllgaard \& Overgaard (2002).

${ }^{15} \mathrm{On}$ the assumption that all rivals play collusively.

${ }^{16}$ Against colluding rivals.

${ }^{17}$ Roughly, if the relevant period is one day, then $\$ \delta$ is the value today of $\$ 1$ accruing tomorrow, while if the relevant period is one year, then $\$ \delta$ is the value today of $\$ 1$ accruing next year. Throughout, we assume that all firms (and customers, if necessary) have the same discount factor/degree of patience. This is without much loss of generality. If firms had different discount factors, then the critical conditions below would, instead, be associated with the least patient firm. 
We can write this more conveniently as

$$
\frac{\delta}{1-\delta} D[\text { eterrence }] \geq T[\text { emptation }]
$$

or

$$
\delta \geq \underline{\delta} \equiv \frac{T}{T+D}
$$

where $D \equiv \pi^{C}-\pi^{N}$ and $T \equiv \pi^{D}-\pi^{C}$, while $\underline{\delta}$ denotes the critical discount factor required to sustain (perfect) collusion. Thus, the temptation to deviate from collusion (the one-period gain) should be outweighed by (the discounted value of) the future losses. Heuristically, there is always a short-term gain to be had for individual firms from cheating on co-conspirators under tacit collusion. However, if firms are sufficiently patient, this gain will be wiped out by future losses resulting from the more intensive competition once the tacit agreement has been broken. Patience is captured by the discount factor, and anything that increases the (effective) discount factor will facilitate collusion. Hence, to combat collusion, antitrust agencies would be wise to keep a keen eye on factors such as the exchange of information, firm communication and general market transparency which may influence the effective discount factor among oligopolists. This underlies the views on antitrust vis a vis tacit collusion espoused by Kühn \& Vives (1995), Kühn (2001), Halliday \& Seabright (2001) and Møllgaard \& Overgaard (2001) on which the following relies heavily. ${ }^{18}$

Traditionally, however, antitrust has relied on structural features of an oligopoly, such as concentration (largely, the number of firms), cost commonality and product differentiation, to assess whether tacit collusion is likely or not in a given market. This presents several empirical and practical problems: difficulty of estimating demands for individual products, difficulty of assessing (let alone, bringing down) entry barriers, and difficulty of estimating cost functions. Without getting into the details, we alert the reader to Kühn (2001) for a very critical perspective on how to make economic theory and econometrics operative and useful from the point view of practical antitrust; notably with a view to establishing proof suitable in a court-of-law.

The type of condition in (1) is representative of how modern oligopoly theory studies the possibility of collusion in dynamic settings. Below, we shall study in more detail how the critical elements are affected by changes in the information flows on either side of the market. Subsequently, we try to illustrate some of the main points with reference to a series of cases from both sides of the Atlantic.

With this in mind, we can use variations on the canonical set-up above to illustrate the main points. Suppose we refer to $i_{f}$ as (some "index" of) information available to firms and $i_{c}$ as information available to potential customers. Below, we shall generally assume that $i_{f}$ and $i_{c}$ are both numbers between 0 and 1. Thus, if $i_{f}=1$ (resp. $i_{c}=1$ ), we shall say that the market is fully transparent from the perspective of firms (resp., potential customers). In contrast, if $i_{f}=0$ (resp. $i_{c}=0$ ), we shall say that the market is completely non-transparent from the perspective of firms (resp., potential customers). Recalling the discussion of the various notions of information in the Introduction, let us briefly give a few possible interpretations.

As far as firms are concerned, $i_{f}$ may refer to how accurately and how quickly firms obtain information relevant for their business strategies. Thus, a high value of $i_{f}$ (close to 1 ) could capture that information on the prices or quantities of rivals is obtained quickly, allowing the firm in question to respond quickly to changes in rival behavior. Similarly, a low value of $i_{f}$ (close to 0 ) could capture that deviations by rivals from tacitly collusive behavior is only detected with a small probability (due, e.g. to the secrecy of price cutting).

As far as potential customers are concerned, $i_{c}$ may capture the detail with which potential customers are able to observe individual firm prices or product characteristics. Thus, a high value of $i_{c}$ (close to

\footnotetext{
${ }^{18}$ For an authoritative text book treatment, see Tirole (1989, ch. 6).
} 
1) may signify that the prices charged by individual firms can be observed easily and at low cost (due, e.g., to the access to free and efficient online shop-bots). A low value of $i_{c}$ (close to 0 ) could represent that it is intrinsically difficult or expensive for potential customers to gather information on product characteristics associated with goods or services from different firms.

With these (and other) interpretations in mind, we shall refer to information exhange, communication and improved market transparency as something that either increases $i_{f}, i_{c}$ or both. Then, in a given model, we would obtain a condition on the discount factor required to sustain tacit collusion of the form

$$
\delta \geq \underline{\delta}\left(i_{f}, i_{c}\right)
$$

where generalized notions of "temptation", $T=T\left(i_{f}, i_{c}\right)$, and "deterrence", $D=D\left(i_{f}, i_{c}\right)$, enter in the exact specification of the right-hand side as we shall see. For example, that the temptation to cheat is dependent on $i_{c}$ is easily understood: if potential customers are unable to observe the price being slashed by a particular firm, then the lure of deviation disappears, since a deviating firm would end up selling mostly to existing customers at lower prices. Similar arguments reveal that the temptation to cheat and the deterrence from cheating generally depend on information available on both sides of the market.

In the next two subsections we present more detailed commentary on the the likely effects of information flows on the firm side as well as the customer side of the market. We do so sequentially, in the sense that we first look at changing information flows on the firm side, while fixing the information on the customer side, and next turn to changing information flows on the customers side, while fixing information on the firm side. Ultimately, in the last subsection, we try to bring things together. This is, of course, of utmost importance for antitrust practice, since regulatory attempts to "cure" problems on one side of the market may have repercussions (positive or negative) on the other side of the market. This has sometimes been overlooked in the past, as illustrated by some of the cases discussed.

\section{Strategic uncertainty and partial collusion}

So far in this section, we have focused on the scope for collusion, in the sense that we have limited attention to the perfectly collusive outcome (a version of monopoly market sharing). This raises (at least) two questions.

First, suppose that the discount factor (degree of firm-patience) is too small to allow the perfectly collusive outcome to be sustained as an equilbrium. Does this mean that firm have to revert to the fully non-collusive outcome, or is there some form of partial collusion, which may be sustained by the firms? In Møllgaard \& Overgaard (2001) we address this issue, and the key results may be summarized as follows. Partial collusion may sometimes be sustained, when perfect collusion is unsustainable. Partial collusion could e.g. be taken to mean that rather than sharing monopoly outputs, as under perfect collusion, the firms symmetrically expand outputs to some level between monopoly outputs and the fully non-collusive outputs. This may just imply that the temptation to cheat for individual firms is decreased enough to sustain tacit agreement. Møllgaard \& Overgaard (2001) then go on to study how the sustainability of partial collusion is related to the information flows on both sides of the market, in much the same way as suggested in the following two subsections.

Secondly, and more importantly, the analysis up to this point has merely shown that collusion may be sustained as an equilibrium outcome. The analysis has not shown that perfect collusion is the only possible or likely outcome of the dynamic oligopoly competition. In fact, it may be shown that dynamic oligopoly interaction where firms expect (or plan) to be around indefinitely will typically allow many equilibrium configurations, if the firms are sufficiently patient. ${ }^{19}$ With many possible equilibria, it is not immediately obvious how firms may decide to play. In the literature, this is referred to as strategic uncertainty. In order to develop a sustainable behavioral pattern in the dynamic oligopoly interaction, the rival firms have

\footnotetext{
${ }^{19}$ In the literature this is formalized by what is referred to as the Folk Theorem, since no one has been bold enough to claim the result (see Tirole $(1989$, ch. 6) or Fudenberg \& Tirole (1991, ch. 5)). In the present setting setting this implies 1) that anything from no collusion to perfect collusion is possible, and 2) that asymmetric profit assignments are sustainable, provided that firms are sufficiently patient.
} 
to arrive at some common understanding. But how is such a common understanding to develop without some form of communication between the rivals? Communication over how to play some game may be referred to as cheap talk, but it should be evident that such "talk" (communication) may be critical to enabling a "meeting of minds". Notice how this communication relates to future intentions, whereas the information referred to in the canonical game above related to past bahavior (prices, quantities, etc.). The upshot of this is that information about past behavior and communication about future intentions seem to play somewhat different roles in oligopolistic coordination and tacit collusion. Once firms have agreed on how to play the game, then information about past (and present) behavior seems vital in policing the agreement. On the other hand, before an agreement on how to play the game has been reached, the ability to communicate one's future intentions appear critical to eventually developing such an agreement. This distinction will play an important role in Section 4 below.

\subsection{Information flows between firms}

We now illustrate that small variations on the canonical model above allow us to capture both detection lags and cases where deviations are only observed by rivals with some probability. Detection lags and uncertain detection can be seen as attempts to model what has loosely been referred to as secret price cutting, thus, as formalizations of imperfect information flows on the firm side. A detection lag means that chiseling on an implicit agreement can be kept secret by the transgressor for some time, while a small probability of detection implies that a transgressor expects to walk away "scott free" with significant probability. Also, lumpy and infrequent orders will have roughly the same effect as a detection lag, since this is comparable to assuming that the next round of play is far into the future. Tirole (1988, p. 248) makes the following general remarks.

"The threat of a punishment operates only if the punishment comes fairly soon after a price cut. Punishment might be delayed for two related reasons. First, a firm's price cut may be learned of by its rival only with a lag. This may happen when manufacturers contract with a few big buyers (wholesalers or downstream manufacturers). The secrecy of contracts may then be an obstacle to collusion. Indeed, if price cuts were never detected, collusion could not be sustained. Second, infrequent interaction (due to lumpiness in orders, for instance) delays the punishment and makes current price cutting more attractive."

\subsubsection{Detection lags}

Now, consider a repeated game with a detection lag in canonical form. Within the model outlined above, assuming that there is a detection lag of $s$ periods ${ }^{20}$ is tantamount to assuming that deviations from some tacit or explicit agreement is observed by rival firms with a lag of $s$ periods. That is, if a firm deviates in period $t$, this will be detected by the rivals at the end of period $t+s$, and punishment/retaliation can start in period $t+s+1$. Thus, with this notational convention, in the basic model above without detection lag $(s=0)$, the deviation is detected at the end of period $t$, and the punishment/retaliation can start in period $t+1$. Further, to keep close to the notation above, we may say that the detection lag is related to the index of information on the firm side, $s=s\left(i_{f}\right)$, with $s(1)=0$ (no detection lag) and $s\left(i_{f}\right) \rightarrow \infty$ for $i_{f} \rightarrow 0$ (infinite detection lag). Immediately below we simply fix $i_{c}$ when discussing information flows on the firm side.

For comparison with the analysis in the baseline canonical case, we again consider whether firms are able to collude perfectly with resulting collusive profits in every period of $\pi^{C}$. As above, firms are restricted to Nash trigger-strategies. By following the collusive path a firm still obtains

$$
V^{C}=\frac{1}{1-\delta} \pi^{C}\left(i_{c}\right)
$$

\footnotetext{
${ }^{20} s$ could be hours, days, weeks, months, quarters, etc., depending on the specific case under scrutiny.
} 
By deviating until detected, the deviating firm obtains

$$
V^{D}=\left(1+\delta+\delta^{2}+\ldots+\delta^{s\left(i_{f}\right)}\right) \pi^{D}\left(i_{c}\right)+\delta^{s\left(i_{f}\right)+1}\left(1+\delta+\delta^{2}+\ldots\right) \pi^{N}\left(i_{c}\right)
$$

That is, by deviating a firm receives the deviation profits for $s\left(i_{f}\right)+1$ periods, after which the profits in every period coincide with the static Nash Equilibrium profits forever. The discounted value of this stream of profits can be rewritten as

$$
V^{D}=\frac{1}{1-\delta} \pi^{D}\left(i_{c}\right)-\frac{\delta^{s\left(i_{f}\right)+1}}{1-\delta}\left(\pi^{D}\left(i_{c}\right)-\pi^{N}\left(i_{c}\right)\right)
$$

Hence, to sustain perfect collusion, it must be the case that $V^{C} \geq V^{D}$, which we can write as ${ }^{21}$

$$
\delta \geq \underline{\delta}\left(i_{f}, i_{c}\right)=\sqrt[s\left(i_{f}\right)+1]{\frac{T\left(i_{c}\right)}{T\left(i_{c}\right)+D\left(i_{c}\right)}}
$$

$>$ From this it is immediately clear, and not very surprising, that the critical discount factor, $\underline{\delta}\left(i_{f}, i_{c}\right)$, is increasing in the detection lag, $s\left(i_{f}\right)$, that is, the delay before rivals detect a deviation and start responding. So, absence of market transparency from the perspective of firms, interpreted as long detection lags or lumpy orders, is good from the perspective of antitrust, in the sense that it makes tacit collusion harder to sustain.

\subsubsection{Uncertain detection}

Next, consider a repeated game where deviations are only observed with a certain probability. To capture this idea as simply as possible, let us assume that a deviation from a tacit agreement is only detected with a probability $i_{f}$, which is some number between 0 and 1 . If a deviation is detected, then it is detected immediately. So, the standard model is simply one where $i_{f}=1$. Hence, in this case the index of information on the firm side, $i_{f}$, simply coincides with the probability of detection. Again, we simply fix information on the customer side at some level $i_{c}$.

We study the scope for sustaining perfect collusion with resulting profits per period given by $\pi^{C}$. As above a firm which follows the collusive path obtains discounted payoffs of

$$
V^{C}=\frac{1}{1-\delta} \pi^{C}\left(i_{c}\right)
$$

while a firm contemplating a deviation (once and then return to the prescribed strategies ${ }^{22}$ ) expects to obtain

$$
V^{D}=\pi^{D}\left(i_{c}\right)+\delta\left(i_{f} \cdot \frac{1}{1-\delta} \pi^{N}\left(i_{c}\right)+\left(1-i_{f}\right) V^{C}\right)
$$

Perfect collusion requires $V^{C} \geq V^{D}$, which we can express $\operatorname{as}^{23}$ Or, in the notation introduced above

$$
\delta \geq \underline{\delta}\left(i_{f}, i_{c}\right) \equiv \frac{T\left(i_{c}\right)}{T\left(i_{c}\right)+i_{f} D\left(i_{c}\right)}
$$

from which it is immediately obvious that the critical discount factor, $\underline{\delta}\left(i_{f}, i_{c}\right)$, is decreasing in the probability of detection, $i_{f}$. Again, absence of transparency, interpreted as low probabilities of detecting deviation (e.g., price cuts), is good from the perspective of antitrust, for the same reason as long detection lags.

\footnotetext{
${ }^{21} V^{C} \geq V^{D}$ can be written as $\frac{1}{1-\delta} \pi^{C}\left(i_{c}\right) \geq \frac{1}{1-\delta} \pi^{D}\left(i_{c}\right)-\frac{\delta^{s\left(i_{f}\right)+1}}{1-\delta}\left(\pi^{D}\left(i_{c}\right)-\pi^{N}\left(i_{c}\right)\right)$. Rearranging, we obtain $\delta^{s\left(i_{f}\right)+1} \geq$ $\frac{T\left(i_{c}\right)}{T\left(i_{c}\right)+D\left(i_{c}\right)}$, from which the result follows.

${ }^{22}$ Formally, this is, of course, equivalent to deviating in every period until detected.

${ }^{23} V^{C} \geq V^{D}$ can be written as $\frac{1}{1-\delta} \pi^{C}\left(i_{c}\right) \geq \pi^{D}\left(i_{c}\right)+\frac{\delta}{1-\delta}\left(i_{f} \pi^{N}\left(i_{c}\right)+\left(1-i_{f}\right) \pi^{C}\left(i_{c}\right)\right)$ and by rearranging, we obtain $\delta \geq \frac{\pi^{D}\left(i_{c}\right)-\pi^{C}\left(i_{c}\right)}{\pi^{D}\left(i_{c}\right)-\pi^{C}\left(i_{c}\right)+i_{f}\left(\pi^{C}\left(i_{c}\right)-\pi^{N}\left(i_{c}\right)\right)}$. Now, using the definitions of $T$ and $D$, the result follows.
} 


\subsection{Information flows on the consumer side}

When scrutizing the effects of information flows on the customer side, there are two effects we need to balance. On the one hand, an improvement in customer information might be expected to increase individual firm incentives to cheat on tacitly agreed (high) prices or (low) outputs. The more informed potential customers are, the more sensitive are individual firm demands to changes in the strategic choice of the firm in question. So, in a static, one-shot game, increased transparency on the customer side should intensify competition and lower the resulting (static) equilibrium profits. On the other hand, improved customer information would also tend to decrease the lower bound on continuation-payoffs in subgame perfect equilibria; hence, (credible) punishments become more severe. So, through this effect, tacit collusion in a dynamic game may be said to be facilitated by increased transparency. The overall conclusions, thus, turn on the trade-off between the increased one-period gain from reneging and the increased severity of punishments.

The main idea may be explained quite generally with reference to the canonical stage-game. For ease of exposition, assume that $i_{f}=1$, so that the market is fully transparent from the perspective of firms. ${ }^{24}$ Therefore, we simply suppress $i_{f}$ for notational convenience below. Now, consider a symmetric oligopoly, and let $i_{c}$ between 0 and 1 , be the measure of market transparency from the perspective of (potential) customers. If $i_{c}=0$, then the market is said to be completely non-transparent, and each customer is fully locked into a particular firm, as if he does not know the existence of the other firms. Effectively, this is the case of a number of local monopolies, since the customers of one firm are completely unresponsive to the actions of the other firms. In contrast, if $i_{c}=1$, then the market is said to be perfectly transparent. ${ }^{25}$ Suppose that for a given $i_{c}$, the stage-game has a unique Nash Equilibrium with associated profits for each firm given by $\pi^{N}\left(i_{c}\right)$. In more specific examples, $\pi^{N}\left(i_{c}\right)$ might naturally be assumed to be strictly decreasing in $i_{c}$, capturing that (static) competition becomes more intense the more transparent is the market from the point of view of potential customers. If the firms managed to collude, then profits would be $\pi^{C}\left(i_{c}\right)$. As above, we would expect that $\pi^{C}\left(i_{c}\right)>\pi^{N}\left(i_{c}\right)$ for all positive $i_{c}$. In a specific example, we could assume $\pi^{C}\left(i_{c}\right)=\pi^{C}$, i.e. collusive payoffs are independent of market transparency. Finally, on the assumption that the rivals all play the collusively, there is some best deviation giving rise to one-shot profits of $\pi^{D}\left(i_{c}\right)$ to the defector, where $\pi^{D}\left(i_{c}\right)>\pi^{C}$ for all positive values of $i_{c}$. Again, we might naturally assume that $\pi^{D}\left(i_{c}\right)$ is strictly increasing in $i_{c}$, capturing that the temptation to defect is increasing in transparency. ${ }^{26}$

With this notation, and on the additional assumption that the firms are restricted to simple Nash trigger-strategies in the repeated game, our main point can be stated as follows: Assuming identical discount factors across firms, $\delta$, following a collusive path gives a firm discounted payoffs of

$$
V^{C}=\frac{1}{1-\delta} \pi^{C}\left(i_{c}\right)=\pi^{C}\left(i_{c}\right)+\frac{\delta}{1-\delta} \pi^{C}\left(i_{c}\right)
$$

whereas deviating gives

$$
V^{D}=\pi^{D}\left(i_{c}\right)+\frac{\delta}{1-\delta} \pi^{N}\left(i_{c}\right)
$$

For collusive pricing in every period to be sustainable, thus, requires

$$
\delta \geq \underline{\delta}\left(i_{c}\right) \equiv \frac{T\left(i_{c}\right)}{T\left(i_{c}\right)+D\left(i_{c}\right)}
$$

\footnotetext{
${ }^{24}$ The analysis to follow can easily be adapted to accommodate detection lags or uncertain detection along the lines suggested in the preceding subsection.

${ }^{25} \mathrm{As}$ a reference point, one could imagine a case where the goods offered by the firms are perfect substitutes, the potential customers know this, and they observe all prices before they make any purchases (viz. something close to the standard Bertrand-model).

${ }^{26}$ Fleshing out the details of a perfectly standard oligopoly model with the properties outlined above is done in Møllgaard \& Overgaard $(2001,2002)$.
} 
Thus, both the numerator, $T\left(i_{c}\right)$, and the denominator, $T\left(i_{c}\right)+D\left(i_{c}\right)$, in $(5)$ depend on the the measure of transparency as seen from the perspective of the potential buyers/customers. Given this form of the critical discount factor, it is clearly too much to hope for robust monotonicity results on the relationship between the measure of transparency and the critical discount factor. Also note that it is not immediately clear whether the accommodation of (theoretically) optimal punishments might change this. ${ }^{27}$

In words, we can state the following result. ${ }^{28}$ The required discount factor to sustain full collusion, $\underline{\delta}\left(i_{c}\right)$, is (locally) increasing (decreasing) in the measure of transparency, if the temptation to cheat is more (less) sensitive to transparency than the deterrence. ${ }^{29}$ Whether increased market transparency facilitates or hinders tacit collusion would be expected to depend on the fine details of the market under scrutiny, but general and sweeping policy statements certainly seem unwarranted. Add to this doubts concerning the information and instruments available to policy-makers, and it should be clear that increased transparency could well be a mixed blessing for potential customers.

\subsection{Pulling things together}

Consider information flows among firms first. As suggested above, the traditional focus in the economics literature has been on the flow of information between rival oligopolists. At least since the seminal contribution of Stigler (1964), it has been part of the "folklore" of Industrial Organization that oligopolists will strive towards a monopoly-like coordinated, armed truce characterized by high prices and limited quantities, but that such a state of coordination is difficult to attain for any length of time, unless rather detailed, firm-specific information flows liberally between the firms. Heuristically, the firms may well have a common interest in keeping prices high, but they also have strong individual motives to undercut and steal business from each other.

Hence, with a view to the assessment of information flows, the central lesson is as follows. Improved information flows between oligopolist rivals, through shortened detection lags, increased precision of observations, more detailed communication about future intentions, etc., have the tendency to increase the scope for coordinated behavior (whether tacit or explicit). For example, improved monitoring of the present and recent past strategic choices of rivals (such as prices, contracted quantities, capacities, etc.) enables the detection of individual deviations from collusive "agreements". This implies that "punishments" can be activated more quickly and can be made more precise, that is, they can be fitted to hit mainly the transgressor rather than at random. Thus, the punishment is more severe and therefore serves more effectively as a deterrent. Similarly, improved communication about future intentions makes it easier for the oligopolist rivals to resolve the strategic uncertainty and agree to a mode of coordinated practice. In the presense of multiple equilibria in the dynamic game, it is important that firms arrive at some common understanding of how to play the game. Communication about future intentions contributes to this. ${ }^{30}$

Thus, the exchange of information and communication between firms will often facilitate coordination (tacit collusion), and under a wide set of circumstances it will run counter to the efficiency objective of

\footnotetext{
${ }^{27}$ For more on optimal punishments in oligopoly models, see Abreu (1986), Lambertini \& Sasaki (1999) and Møllgaard \& Overgaard (2002).

${ }^{28}$ Formal details can be found in Møllgaard \& Overgaard (2001, 2002).

${ }^{29}$ Formally, we can state the following "lemma": $\frac{d \underline{\delta}\left(i_{c}\right)}{d i_{c}} \gtreqless 0$ is equivalent to $\frac{d T\left(i_{c}\right) / T\left(i_{c}\right)}{d i_{c} / i_{c}} \gtreqless \frac{d D\left(i_{c}\right) / D\left(i_{c}\right)}{d i_{c} / i_{c}}$. And the proof would go roughly as follows: Suppose that all the functions defined are differentiable. Then, we note that $\frac{d D\left(i_{c}\right)}{d i_{c}}=$ $-\frac{d \pi^{N}\left(i_{c}\right)}{d i_{c}}>0$ and $\frac{d T\left(i_{c}\right)}{d i_{c}}=\frac{d \pi^{D}\left(i_{c}\right)}{d i_{c}}>0$. Hence, both the temptation and the deterrence are increasing in the measure of transparency. We further note that $\operatorname{sign}\left\{\frac{d \underline{\delta}\left(i_{c}\right)}{d i_{c}}\right\}=\operatorname{sign}\left\{\left(T\left(i_{c}\right)+D\left(i_{c}\right)\right) \frac{d T\left(i_{c}\right)}{d i_{c}}-T\left(i_{c}\right)\left(\frac{d T\left(i_{c}\right)}{d i_{c}}+\frac{d D\left(i_{c}\right)}{d i_{c}}\right)\right\}$. The "lemma" then follows immediately from rearranging the right-hand side in "elasticity terms." Thus, sensitivity in the text should be understood in the sense of elasticity (percentage change in dependent variable following a 1 percent change in independent variable).

${ }^{30}$ For more on cheap talk communication, see e.g. Farrell \& Rabin (1996) for an overview and Kühn (2001) for a discussion related specifically to antitrust practice.
} 
antitrust (efficient allocation of scarce resources). However, information dissemination may also serve to improve firm planning and efficiency. Finally, if we include on the firm side all potential entrants, then improved information flows might also facilitate entry, in the sense that it allows potential entrants to spot profit opportunities more effectively. The latter immediately points to an important distinction from the perspective of antitrust between exchanges of information between firms which are kept proprietary and those that leak to potential competitors. Sound antitrust practice has to strike a balance between these contrasting effects of information exchange and communication between firms.

Turning to information flows on the consumer side, the most immediate effect of improved consumer information is to make individual consumers less locked to particular firms (or, less captive, in the jargon of economists). Within the framework of most static oligopoly models, the demand function facing each firm becomes more sensitive to differences between the firm's own price and those of its rivals. As a consequence, static price competition is likely to become intense. ${ }^{31}$ From the perspective of static modelling, it is a relatively robust result that improved consumer information tend to promote the efficiency objective. However, it remains an open question whether this qualitative result is robust to embedding the basic static models in an explicitly dynamic model of oligopoly competition. The reason why this is not intuitively obvious is simple: if improved information on the consumer side makes it easier for a firm to steal customers from its rivals, it must also make it easier for these rivals to "steal" them back again! So, the result might just be that no one tries to steal customers from rivals in the first place.

In the abstract, it is unclear whether one effect or the other dominate. Further specializations of the theoretical model and, ultimately, empirical assessment are needed. Nilsson (2000), Møllgaard \& Overgaard $(2001,2002)$ as well as Schultz $(2004,2005)$ present different formalizations and reach somewhat different results. Thus, "the Devil's in the detail", and sweeping policy statements based on a particular model seem unwarranted, unless it can be documented that the particulars are descriptively accurate. Conservatively, though, it might be argued that it seems easier to write down a fully specified model in which improved information on the consumer side promotes competition (at least, in the sense of making collusion harder to sustain). Similarly, the theoretical contributions seem to indicate that increasing the number of firms makes it more probable that improved consumer information enhances dynamic oligopoly competition. With few firms (2 - 5, say), full market transparency may not be optimal, in the sense of making coordinated behavior most difficult. ${ }^{32}$

In the applied and policy-oriented literature, e.g., OECD (2001) and Kühn (2001), the consensus seems to be that the positive effects of improving consumer information dominate. Thus, it is concluded that, seen in isolation, improved consumer information tends to enhance competition. ${ }^{33}$ To a large extent, this forms the basis for recommendations of public intervention to facilitate price comparisons and establishment of (online) shopbots. In addition, the need for public intervention in information dissemination may also be motivated by the public goods elements and externalities involved in the production and acquisition of information: information produced or gathered tend to spillover to others, and as a result individual agents may have limited incentives to incur the associated costs. Hence, too little or no information may be collected.

Pulling the two sides of the market together, we may (tentatively) conclude that improved information flow on the firm side will likely enhance the scope for coordinated firm behavior, while improved information flows on the consumer side may enhance competition. Antitrust has to strike a balance. Ideally, antitrust practice should attempt to promote an infomation regime, in which potential customers and entrants are well informed about prices, product characteristics, contract terms, etc., while actual competitors are covered by a veil of ignorance with respect to the actions of their rivals. This regime would promote comparison shopping and entry, while at the same time provide incentives for actual competitors to steal business from each other through (secret) discounts and pricing near cost. This

\footnotetext{
${ }^{31} \mathrm{M} \varnothing$ llgaard \& Overgaard $(2001,2002)$ provide fully worked-out model examples to this effect.

${ }^{32}$ For a formalization of this result, see Møllgaard \& Overgaard (2002).

${ }^{33}$ That is, if information on the consumer side can somehow be improved without at the same time affecting information on the firm side, which might work in the opposite direction. For more on this, see below.
} 
regime, of course, is largely a caricature, and it is hard to imagine how, in practice, information can flow freely to consumers (and potential entrants) while at the same time being inaccessible to active firms. Generally, we would suggest that it is difficult to change the flow of information on one side of the market, while leaving the flow on the other side unaffected. This should be kept in mind whenever regulatory intervention is contemplated.

\section{Example}

We leave this discussion with a hypothetical example. Consider an industry in which secret discounts are prevalent. Given the prevalence of discounts, a firm losing business will be in doubt as to whether this is caused by other firms charging low prices in an attempt to steal business, or whether it is due to a slump in demand. ${ }^{34}$ Suppose that the firms in the industry are able to create an institution for information exchange. ${ }^{35}$ Then it will be easier for each individual firm to determine whether it is losing business to aggressive competitors or due to a decrease in demand. Such an information exchange, where individual transactions (invoice) prices and quantities are registered, seems like an ideal institution to support coordinated behavior, since it enables an accurate identification of firms who might have decreased prices or increased sales. The problem for such an institution is how to verify the reported information, since individual firms have an incentive to misrepresent prices and sales. From the perspective of firms, it might be ideal if a government agency (with its authority, coercive powers and ability to prosecute false reporting) required the publication of actual transactions prices and quantities sold. ${ }^{36}$

Secret discounts make the market non-transparent from the perspective of both buyers and sellers. Therefore, coordinated firm behavior is impossible. By eliminating the secrecy surrounding individual transactions prices, (strategic) punishments can be made harsher and more precise, that is, more effective. This leaves the question: what was the purpose of the information exchange? In most recorded cases, the logic seems to be that comparison shopping by the buyers is facilitated by the information exchange. Empirically, however, the effect often seems different, in the sense that firms are not prevented from using the same pieces of information to coordinate their behavior. ${ }^{37}$

\section{Lessons for Antitrust}

Based on the kind of theoretical considerations outlined in the preceding two sections and the role played by information dissemination and communication in sustaining coordinated firm behavior, some key lessons for antitrust can be drawn. Kühn (2001) presents a set of operative criteria on how oligopolistic coordination can be limited. The point of departure is the inherent difficulty of identifying - ex post the intensity of competition in a given market from observing market data. ${ }^{38}$ Thus, Kühn (2001, p. 3) states that

“...competition policy rules cannot systematically rely on the evaluation of price and sales patterns in the relevant market but have to focus instead on observed communication between firms."

With explicit reference to empirical identification problems, Kühn (2001, p. 5) notes that

\footnotetext{
${ }^{34}$ See Green \& Porter (1984) for a formalization of this type of uncertainty regarding rival behavior and, thus, an explicit modelling of some of the points raised by Stigler (1964). Green \& Porter explicitly tie their theoretical contribution to some early experiences from the US railroad industry. See also Porter (1983), Ellison (1994) and Tirole (1989, ch. 6).

${ }^{35}$ Together with whatever verification measures might be needed.

${ }^{36}$ In the academic literature there are several studies of the consequences of this type of public intervention. Below, we shall briefly comment on contract disclosure rules and US rail freight rates (see Fuller, Ruppel \& Bessler (1990) and Schmitz \& Fuller (1995)) as well as the collection and publication of Danish ready-mixed concrete prices (see Albæk, Møllgaard \& Overgaard (1997)).

${ }^{37} \mathrm{Cf}$. the references in the preceding note and the discussion below in Section 5.

${ }^{38} \mathrm{In}$ addition to Kühn (2001), the following is based in large part on OECD (2001) and Møllgaard \& Overgaard (2001).
} 
"[i]t is typically impossible for a court to establish with any accuracy whether oligopolists have charged prices close to monopoly prices or not. In the vast majority of cases the available data will not allow making such inferences....These problems will be compounded by the lack of econometric expertise in most antitrust authorities, which creates the danger of unwarranted strong conclusions from inconclusive data in enforcement practice." 39

A change of focus in antitrust practice vis a vis oligopolistic coordination is therefore recommended. Rather than primarily basing analysis on market data such as prices and quantities, the focus should be moved to other practices which are suspected of facilitating coordination. In particular, communication between market participants should be scrutinized. Such a change of focus would represent a shift from ex post detection and punishment (which is probably a losing battle for the authorities anyway) to $e x$ ante limitation of the scope for collusion and facility of coordination.

Thus, to Kühn (2001) communication between competitors should take center stage, while the implications of this communication for potential customers and entrants (whether direct or indirect) play a supporting role. With reference to the preceding section, two main types of communication between firms may be identified:

1. Communication about planned future behavior and conduct.

2. Communication about past and present behavior and conduct.

Kühn refers to communication about planned, future conduct as soft and non-verifiable information about intentions. This information can relate to planned, future prices, planned production, launch of new products or services, planned capacity changes, etc. In contrast, communication about past and present conduct can be referred to as hard and verifiable information. Examples include past and present prices, contents of order book, investments made, input prices in contracts made with suppliers and information about individual or groups of customers. For each of these types of communication, the antitrust authority should ask the question: what is the potential of the communication with respect to facilitating coordination or collusion? In addition: what are the possible efficiency-enhancing effects of the communication, and are there ways in which these can be realized without the communication?

If the first question returns the answer that a certain type of communication has a strong coordinating potential, then a ban on this communication should be considered. If, in addition, the second question returns the answer that the communication has no possible (or probable) efficiency-enhancing effects, or that these could be attained through other means, then the ban should be placed.

For both main types of communication, a distinction can be made between whether the communication is private or public. In the present context, private communication implies that it is exclusive to the firms, while public communication is transmitted also to potential customers and entrants. Against the theoretical background painted above, this distinction is noteworthy, given that our (informed) prior is that communication between oligopolistic competitors, which does not leak to the public, may have a strong coordinating potential. ${ }^{40}$ In particular, from the perspective of firms, the reservation of communication about planned, future behavior to a private forum would seem to have a significant potential with respect to solving problems of strategic uncertainty. ${ }^{41}$ If oligopolistic rivals are able to communicate

\footnotetext{
${ }^{39} \mathrm{On}$ this, we could add that academic economists have often been puzzled by the weight attached to price patterns in antitrust procedings. Whether prices are rising, falling, dispersed or move in unison says absolutely nothing about the nature of competition, unless they can be tied to some meaningful notion of costs (and movements therein). One is reminded of the following quote from William Landes: "When I took over Aaron's [Director] role of teaching antitrust with a lawyer, Ronald [Coase] said he had gotten tired of antitrust because when the prices went up the judges said it was monopoly, when the prices went down, they said it was predatory pricing, and when they stayed the same, they said it was tacit collusion [laughter]." See, Kitch (1983, p. 193).

${ }^{40}$ We should add, though, that for strategic punishment strategies to work, rivals have to be able to move business around. It is evident that, depending on the particulars of a given market, this may require that some information is leaked to potential customers (that is, customers cannot be too captive).

${ }^{41}$ That is, reaching a meeting of minds on a large set of equilibria.
} 
intentions freely to each other, without committing themselves vis a vis customers, then the adverse efficiency effects may be grave, indeed. ${ }^{42}$

As far as communication about past and present conduct is concerned, a distinction can also be made between whether the information disseminated is aggregated or individualized. The rapid communication of highly disaggregated - firm-specific or transactions-specific - data has a potentially strong effect on the scope for collusion, in the sense that recent and accurate information on the conduct of individual firms allows rivals to react quickly and precisely to changes in conduct. Aggregated information, such as an industry-level average, has a much more limited coordinating potential. We should note, though, that with a very limited number of firms - say, two or three - aggregation does not conceal much. As a result, antitrust agencies will have to keep a keen eye on the actual loss of information through aggregation.

Paraphrasing Kühn (2001), the following conclusions suggest themselves:

1. Private communication between firms about future prices and production plans should be banned. This type of private communication significantly helps firms on how to play the dynamic oligopoly game to their advantage, and it is hard to spot the potential efficiency benefits of such a private communication.

2. If communication between firms about future prices and production plans takes place in public, and, in particular, if the communication commits firms vis a vis potential customers to a significant extent, then the probable, positive efficiency effects are likely so great that a blanket ban would be counter-productive. Whether, in a specific case, the communication promotes or dampens competition must then rely on a more detailed analysis, but, on a priori grounds, the communication should be allowed.

3. The exchange of individualized information about past and present prices and quantities is highly suspect, in the sense that it has a very significant coordinating potential. In addition, examples in which the exchange of detailed, firm-specific information on prices and quantities is necessary for efficient planning and resource allocation seem rare. To allow an "efficiency defense", it is suggested that firms or groups of firms be given the opportunity to argue and prove that a certain exchange is benign, in order to escape a ban.

4. The exchange of individualized past and present cost and demand data should be handled with care, since the particulars of the market in question will determine whether positive or negetive efficiency effects dominate. This suggests a rule-of-reason treatment with a presumption that the exchange is benign. Thus, the authority should prove its case to obtain a ban on the exchange.

5. The exchanges of aggregated data seem largely innocent. However, the antitrust agency must carefully check the effective extent of the aggregation. The exchange of aggregated information may have a significant efficiency enhancing potential with respect to firm planning. Cases may arise, where even the exchange of aggregated information has adverse effects, but in such cases, the authority should prove its case.

Of course, one might debate the details of these recommendations with reference to the academic literature on oligopoly, but (importantly) they rely on a coherent theoretical frame of reference. In

\footnotetext{
${ }^{42}$ In the next section we provide an example of the communication of future intentions between US airlines. This communication took place within a framework of non-binding price announcements in computer reservations systems. The designs of these reservation systems were such that rival airlines got a sneak-preview of each other's intentions, while customers were shut out. It is evident that intentions could be signaled in a low-cost fashion, and that prices could be retracted and revised quickly, if rivals did not react as expected (or intended). Thus, invitations to collude could be sent out via the system.
} 
addition, they are operative in practice and they "move cases" ${ }^{43,44}$

\section{Representative Cases}

Transparency and information dissemination have been an important part of quite a few antitrust landmark cases. In the following we sketch the most important ones and try to indicate different dimensions along which they fit our modelling framework.

\subsection{A Concrete Case}

The first case may serve to illustrate that improved transparency may, indeed, have significant anticompetitive effects by improving coordination amongst oligopolists. In the early 1990s, the Danish Competition Authority found evidence of lack of competition in the ready-mixed concrete industry. ${ }^{45}$ It worried in particular about persistent rumours of significant individualised confidential discounts. In 1993, as the Danish Competition Act at that time emphasized the role of transparency in promoting competition, the authority decided to gather and publish firm-specific transactions prices for two grades of ready-mixed concrete in three regions of Denmark. The intention was to inform customers of bargain deals in the hope that this would lead buyers to exert a downward pressure on prices. However, following the initial publication, average prices went up by 15-20 percent in less than six month. This compares with inflation of 1-2 percent per year and stable or decreasing costs of input.

It can be ruled out that a business upturn or increasing costs caused the price to increase. Since ready-mixed concrete can only be transported a short distance (20-30 kilometres, depending on local infrastructure), competition is local. In the relevant market around the city of Aarhus only four firms were active and pricing was reported for all of those. These four firms thus constitute a tight oligopoly. That improved transparency lead to improved coordination of their pricing policies appears a natural conclusion from Figure 1. While prices were inititally widely dispersed, after a year of publication the firms seemed to agree on the appropriate level of prices.

There is also evidence that the firms essentially stopped granting large individualised discounts because of the improved transparency. If this was the intention, the Competition Authority could be said to have been successful. However, essentially it unwittingly assisted firms in reducing competition by providing the reliable detection of cheating that is a prerequisite for sustaining collusion; see the section on uncertain detection. This case also illustrates that in an oligopolistic market setting if suppliers are able to react to improved information dissemination before buyers, the latter may be hurt rather than helped by transparency.

In closely related studies, Fuller, Ruppel and Bessler (1990) and Schmitz and Fuller (1995) find that contract disclosure legislation passed by the US Congress increased railroad freight rates as a direct result of the improved scope for tacit collusion. The legislation mandated disclosure of firm-specific information also in this case.

\footnotetext{
${ }^{43}$ Both of these features are in contrast to much of the literature in Industrial Organization on dynamic oligopoly. Folk Theorem-like statements that both highly collusive and highly competitive outcomes are consistent with equilibrium in a given market, and statements to the effect that almost any observed conduct is consistent with both competition and collusion, all point to an ex post, rule of reason regime with all its associated problems of lack of data, arbitrary definition of relevant market, and econometric identification.

${ }^{44} \mathrm{With}$ reference to our earlier remarks on online information dissemination and communication, it is noticable that item 3 on the list above potentially gives rise to reservations with respect to the exchange of information via the internet as advocated by consumer groups and antitrust agencies in some jurisdictions. Halliday \& Seabright (2001) discuss this with explicit reference to Kühns recommendations. See also the "rejoinder" in Kühn (2001, 20-21) and the general comments in Møllgaard \& Overgaard (2001) as well as Frontier Economics (2000) and FTC (2000).

${ }^{45}$ See Albæk, Møllgaard \& Overgaard $(1996,1997)$ for a discussion of the legislation and a full account of the case.
} 


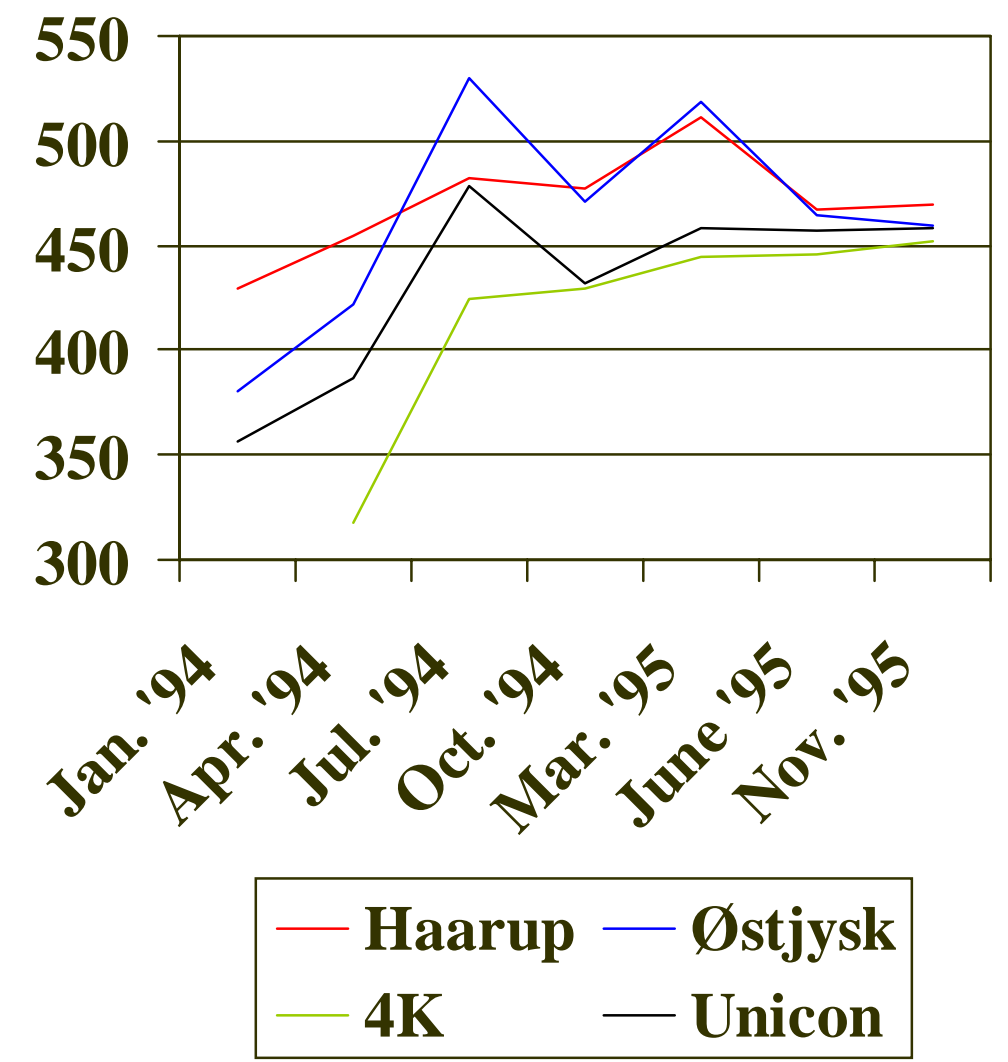

Figure 1: Average concrete prices for the four producers in Aarhus 


\subsection{Cheap Talk in the Air and on the Ground}

In the US, a price-fixing case brought by the Department of Justice against the Airline Tariff Publishing Company $(A T P)$ involved price transparency created by eight major domestic U.S. airlines through ATP, their own joint venture. ${ }^{46}$ ATP collects fare information from the airlines and disseminates it daily to all the airlines and the major computer reservation systems (CRSs) that serve travel agents. ATP thus allows airlines to observe and respond quickly to each other's prices. This already improves the scope for collusion; see the section on detection lags. However, on top of this, ATP may serve as an efficient instrument for cheap talk, i.e. communication that does not commit the airlines to a particular action but allow them to 'negotiate' and coordinate on a collusive outcome.

Essentially, a suggestion to halt an unwanted discount fare could be made unilaterally by a firm by announcing a Last Ticket Day (LTD) for that fare. If other firms follow suit, they go ahead and implement it; if not, the LTD could be changed to a later date or eliminated. Since no trade is made based on the information, no sales are lost before coordination has been achieved. It is in this sense that 'talk is cheap'. In addition, airlines could use a First Ticket Date (FTD) to signal that they suggest a new and higher price or they could threaten a cheater with a punishment strategy of low prices to take effect in the future, if the cheater does not bring prices back in line. The case reveals how 'junk fares' were eliminated through several rounds of proposals and counter proposals that ultimately lead to an increase of junk fares by twenty dollars each way in hundreds of city-pair markets. For one airline it is estimated that this would increase revenues by $\$ 7$ million per month!

The ATP case was settled through consent decrees. All airlines and ATP prohibited FTDs and LTDs so that price changes would become binding and thus potentially costly for the firms. Thus the consent decrees stipulated the end of cheap talk:

"By limiting the ability of the airlines to engage in extensive price negotiations, the government contends that the airlines will find it more difficult to co-ordinate on more collusive outcomes in the future. Whether the decree actually will have this effect remains to be seen, but as co-ordination becomes more costly, it seems unlikely that the airlines will be able to engage in extensive negotiations that link together dozens or hundreds of markets. Multimarket contact may still be present, but without the ability to easily define the terms of an agreement, firms may not be able to exploit their cross-market linkages as fully as before the entry of the consent decree." (Gillespie, 1995, 16)

In the Ivy League case, ${ }^{47}$ college presidents of Ivy League Universities and MIT shared information about prospective tuition increases during their winter budget-planning process, before the public announcement. This was described by one of the involved university officials as "an informal swapping of intentions" - but one that would eliminate strategic uncertainty and increase prices (tuition) on average (see Section 3 above). The cases were ultimately settled with all eight Ivy League Universities and MIT. The U.S. Department of Justice notes:

"These complex arrangements - the Ivy Methodology, the spring meetings to negotiate uniform offers to individual students, the moral exhortations to nurture compliance from cartel members and even non-cartel members - illustrate the role that price transparency plays in a complex, longstanding cartel. It is one of an array of strategies that economise on trust, so that cartel members don't act selfishly in their own interest. Complex conspiracies impose

\footnotetext{
${ }^{46}$ The following exposition draws on OECD (2001, 191-193) that in turn builds on Gillespie (1995).

${ }^{47}$ See OECD (2001) pp. 193-196 for a brief account. The case resulted in consent decrees from the eight Ivy League Universities (U.S. V. Brown University, et al., 1991 WL 536896 (E.D. Pa.)) and a favourable verdict against MIT in district court (805 F. Supp. 288 (E.D. Pa. 1992)). On appeal the appeals court remanded the case to the district court to consider procompetitive and welfare defences for price-fixing (5 F.3d 658 (3d Cir. 1993)). Finally, the case was settled with MIT in December 1993.
} 
great demands for price transparency; and legal constraints on price transparency make it more difficult to sustain complex conspiracies." (OECD, 2001, at pp. 195-196)

The U.S. Federal Trade Commission has also been concerned with unilateral price announcements that were perceived as inviations to collude. The FTC issued a complaint agains Stone Container Corporation (SCC), U.S.'s largest manufacturer of linerboard, in 1998, alleging that when SCC announced a price increase of USD30/tonne for all grades of linerboard to take effect in March 1993, it was effectively inviting rivals to collude. The invitation was turned down since other linerboard manufacturers failed to follow suit. SCC withdrew its announced price increase and pursued other means of organizing improved cooperation (see OECD (2001) at p. 189).

In Europe, the European Commission decided that a number of wood pulp producers had colluded on price announcements and by exchanging information but this decision was ultimately overturned by the European Court of Justice partly because - in contrast to the ATP and SCC cases - there were no subsequent revisions of the announced prices that, thus, were perceived to involve more commitment on the part of the parties. See Kühn and Vives (1995) at section 3.1.1 for an elaboration of this point.

Finally, the Swedish Market Court has recently fined five retail-gasoline chains about $\$ 20$ mill. in a case concerning the coordinated elimination of discounts to major customers. This case is interesting from the perspective of the present paper, since the evidence presented to the court by the Swedish Competition Authority largely turned on the communication between company representatives on their intentions. For details, see Swedish Market Court (2005).

\subsection{Authority at Sea}

For more than a century container shipping has been run through a series of 'liner conferences'. Container shipping provides regular shuttle service in a network connecting ports all around the world. There is a fixed time table and shippers (customers) were charged standard rates that were agreed by the liner conferences. For many years container shipping has enjoyed a special treatment from cartel laws, justified by large investments in vessels and port facilities. However, increasingly antitrust authorities have become wary of granting such exemptions from competition law, arguing that liner conferences were essentially cartels. Thus in 1992, a number of large shipowners notified the European Commission of the TransAtlantic Agreement (TAA). The Commission prohibited the TAA (and price fixing activities that could have the same or similar effects) in 1994. This lead the parties to the TAA to notify the Commission of the Trans-Atlantic Conference Agreement $(T A C A)$ that suggested that the members could agree on the rate, charges and other conditions of carriage using a common tariff. Members of TACA had a market share of arround 70 percent of the trade between Northern Europe and the costs of the USA. ${ }^{48}$

One of the main problems of cartelists is that cooperation tends to break down if detection is uncertain (see the section on uncertain detection). Article 10 of TACA proposed to solve this problem by setting up the 'TACA Enforcement Authority', an independent body to police the duties and obligations of the parties. The TACA Enforcement Authority could investigate any alleged breach of the terms of the agreement on its own initiative or following a complaint. It would have total unfettered access to all documents related to a carriers activity within the TACA and would be authorised to inspect records and property as well as interview and take statements from persons. It would be entitled to impose fines of USD 100,000-150,000 for any breach of the agreement, in particular the various pricing agreements. Furthermore, to support the authority, it was entitled to fine any refusal to allow access by the parties: USD 75,000 for the first instance, USD 150,000 for the second and USD 250,000 for each incident thereafter (within a two-year period). Recidivism, in respect of all breaches, was to be fined by up to USD 300,000 within any one-year period.

\footnotetext{
${ }^{48}$ This case is summarized by Møllgaard (2004). The complete decision is available from the Official Journal of the European Communities L95/1, April 9, 1999 (pp. 1-112); see also EU press release IP/98/811 (Sept. 16, 1998).
} 
The effect of the TACA Enforcement Authority would clearly have been to reduce or eliminate any uncertainty as to whether the agreement is followed by all members. In this manner, it would have served to make cheating on the agreement readily observable and immediately punishable, thus supporting the price fixing agreement. For this reason, the European Commission decided in 1998 to prohibit TACA and fine the parties a total of EUR 273 million. The fine was later (2003) annulled by the European Court of Justice, arguing that the shipping companies had notified the Commission of their cooperation. However, the Court upheld the Commission's contention that the original agreement conflicted with EU competition rules.

Recently, the European Liner Affairs Association has suggested to replace the current liner conferences with an information exchange system the content of which would be to make some information (e.g. monthly capacity utilization forecasts and commodity developments) available only to members of the association, while other information will be made public to shippers as well (e.g. forecasts of demand and quarterly price indices for different types of cargo per trade leg). It remains an open question at the time of writing, whether the European Commission (and possibly the European Court of Justice) will allow such a combination of information to the customers and information to the competitors.

\subsection{Information exchange IS collusion: UK Tractors}

Another EU case sheds light on the importance of detailed and recent information for sustaining collusion. This case is particularly interesting because it was a first, in the sense that explicit allegations of collusion did not enter, and it all turned (in a pure form) on the effects of the information exchange. ${ }^{49}$

In 1988, three trade associations notified the EU Commission about an information exchange agreement (the UK Agricultural Tractor Registration Exchange) that had existed since 1975. The agreement concerned dissemination of detailed information obtained from the UK Department of Transport on retail sales and market shares of eight manufacturers and importers of agricultural tractors in the UK. The market was characterized by high concentration (four-firm concentration ration of 77 percent; eight-firm concentration ration of 87 percent), declining demand and excess capacity.

The Commission did not object to the availability of aggregate industry data, but rather to the dissemination of individualized sales data because it in and of itself was found to restrict competition because it prevented hidden competition in a highly concentrated market and because it was seen to increase barriers to entry for non-members:

"The Exchange restricts competition because it creates a degree of market transparency between the suppliers in a highly concentrated market which is likely to destroy what hidden competition there remains between the suppliers on the market on account of the risk and ease of exposure of independent competitive action. ... Uncertainty and secrecy between suppliers is a vital element of competition in this kind of market. Indeed active competition in these market conditions becomes possible only if each competitor can keep its actions secret or even succeeds in misleading its rivals. ... [T] he high market transparency between suppliers on the United Kingdom tractor makret which is created by the Exchange takes the surprise effect out of a competitor's action thus resulting in a shorter space of time for reactions with the effect that temporary advantages are greatly reduced. " 50

The firms involved opined that the exchange of information was necessary to process warranty claims and for monitoring the sales efforts of its marketing personnel, thus providing an 'efficiency defence'. However, the Commission concluded that such effects could be achieved through the comparison of own

\footnotetext{
${ }^{49}$ The decision is published in the Official Journal of the EU, 1992, L68/19. It is summarized by OECD (2001, 30-31) and subject to extensive treatment by Georgantzis and Sabater-Grande (2002). See also Kühn \& Vives (1995, pp. 96-102), Halliday \& Seabright (2001, pp. 90-92) and Kühn (2001, 195-196).

${ }^{50}$ Official Journal L68, 1992, at para. 37.
} 
company data and aggregate industry data. In general, the EU Commission is less likely to prohibit information exchange the more difficult it is to track individual firms.

This is evident from the EU Commission's Cartonboard ${ }^{51}$ and Wastepaper ${ }^{52}$ cases, the Commission argued that to prevent identfication of individualized information, aggregation of the data of at least three, respectively, four firms would be required. See also Halliday and Seabright (2001) for a discussion of this.

\section{Final Remarks}

Improved information dissemination may improve firms' ability to plan their business decisions to the benefit of society (including customers) and/or allow potential customers to make the right decisions given their preferences. However, increased information dissemination can have significant coordinating or collusive potential to the benefit of firms but at the expense of potential customers.

The balance of these effects depends on the details of the market(s) under scrutiny. In addition it depends on how and why information is communicated.

Antitrust agencies are likely to take a dim view on information that is exchanged privately between firms and will ease up if the information is presented in such a way that individual firms cannot be identified. Similarly, the exchange of old information is less likely to be perceived as offensive than that of new or recent information because of the time lag thus introduced. Exchange of future plans may reduce firms' strategic uncertainty and such cheap talk is likely to raise eyebrows at competition authorities. However, if price announcements are (perceived to be) binding, the antitrust treatment is likely more lenient.

Arguably, however, information exchange has never been easier than today. It is thus an open question what competition authorities can really do about e.g. encrypted online chat rooms that substitute for the smoke-filled parlours of the past. This will likely imply that whistleblowers become much more important in the uncovering of collusion.

\footnotetext{
${ }^{51}$ CEPI - Cartonboard [1996] Official Journal of the EU C310/3.

${ }^{52}$ European Wastepaper Information Service [1987] Official Journal of the EU C339/7.
} 


\section{References}

Abreu, D., 1986, Extremal Equilibria of Oligopolistic Supergames, Journal of Economic Theory 39: 191-225.

Akerlof, G., 1970, The Market for "Lemons": Qualitative Uncertainty and the Market Mechanism, Quarterly Journal of Economics 84: 488-500.

Albæk, S.; H.P. Møllgaard \& P.B. Overgaard, 1996, Law-Assisted Collusion? The Transparency Principle in the Danish Competition Act, European Competition Law Review 17: 339-43.

Albæk, S., H.P. Møllgaard \& P.B. Overgaard, 1997, Government-Assisted Oligopoly Coordination? A Concrete Case, Journal of Industrial Economics 45: 429-443.

Ellison, G., 1994, Theories of Cartel Stability and The Joint Executive Committee, RAND Journal of Economics 25: 37-57.

Farrell, J., \& M. Rabin, 1996, Cheap Talk, Journal of Economic Perspectives 10: 103-118.

Frontier Economics, 2000, E-Commerce and Its Implications for Competition Policy, Discussion Paper, Office of Fair Trading, London: UK.

FTC, 2000, Entering the 21st Century: Competition Policy in the World of B2B Electronic Market Places, Staff Report, Federal Trade Commission, Washington: DC.

Fudenberg, D., \& J. Tirole, 1991, Game Theory, MIT Press, Cambridge: MA.

Fuller, S., F. Ruppel \& D. Bessler, 1990, Effects of Contract Disclosure on Price: Railroad Grain Contracting in the Plains, Western Journal of Agricultural Economics 15: 265-271.

Georgantzís, N. and G. Sabater-Grande, 2002, Market Transparency and Collusion: On the UK Agricultural Tractor Registration Exchange, European Journal of Law and Economics 14: 129-150.

Gillespie, W., 1995, Cheap Talk, Price Announcement, and Collusive Coordination, Discussion Paper EAG 95-3, Economic Analysis Group, Antitrust Division, U.S. Department of Justice, Washington: DC.

Green, E., \& R. Porter, 1984, Non-Cooperative Collusion Under Imperfect Price Information, Econometrica 52: 87-100.

Halliday, J. \& P. Seabright, 2001, Networks Good, Cartels Bad: But How Could Anyone Tell the Difference?, ch. 5 of Fighting Cartels - Why and How?, Swedish Competition Authority, Stockholm: Sweden.

Hayek, F., 1945, The Use of Knowledge in Society, American Economic Review 35: 519-530.

Kitch, E., 1983, The Fire of Truth: A Remembrance of Law and Economics at Chicago, 1932 - 1970, Journal of Law and Economics 26: 163-234.

Kühn, K.-U., 2001, Fighting Collusion: Regulation of Communication between Firms, Economic Policy 32: $1-37$.

Kühn, K.-U., \& X. Vives, 1995, Information Exchanges among Firms and Their Impact on Competition, Office of the Official Publications of the European Communities, Luxemburg. 
Lambertini, L. \& D. Sasaki, 1999, Optimal Punishments in Linear Duopoly Supergames with Product Differentiation, Journal of Economics 69: 173-88.

Møllgaard, H.P., 2004, TACA, Case study, Department of Economics, Copenhagen Business School.

Møllgaard, H.P. \& P.B. Overgaard, 2001, Market Transparency and Competition Policy, Rivista di Politica Economica 91: 11-58 (reprinted in M. Baldassarri \& L. Lambertini (eds.), Antitrust, Regulation and Competition, Palgrave Macmillan, Basingstoke: UK, 2003.

Møllgaard, H.P. \& P.B. Overgaard, 2002, Market Transparency: A Mixed Blessing?, mimeo, Departments of Economics, Copenhagen Business School \& University of Aarhus.

Nilsson, A., 2000, Transparency and Competition, mimeo, Stockholm School of Economics.

Nitsche, R. \& N. von Hinten-Reed, 2004, Competitive Impacts of Information Exchange, Charles River Associates, Brussels: Belgium.

OECD, 2001, Price Transparency, Document DAFFE/CLP(2001)22, Paris: France.

Porter, R., 1983, A Study of Cartel Stability: The Joint Executive Committee, Bell Journal of Economics 14: 301-314.

Schmitz, J., \& S. Fuller, 1995, Effects of Contract Disclosure on Railroad Grain Rates: An Analysis of Corn Belt Corridors, Logistics and Transportation Review 31: 97-124

Schultz, C., 2004, Market Transparency and Product Differentiation, Economics Letters 83: 173-178.

Schultz, C., 2005, Transparency on the Consumer Side and Tacit Collusion, European Economic Review 49: 279-297.

Shapiro, C., \& H. Varian, 1999, Information Rules: A Strategic Guide to the Network Economy, Harvard Business School Press, Cambridge: MA.

Smith, A., 1776, An Inquiry into the Nature and Causes of the Wealth of Nations. R.H. Cambell and A.S. Skinner, eds., 1976, Clarendon Press, Oxford.

Stigler, G., 1961, The Economics of Information, Journal of Political Economy 68: 213-225.

Stigler, G., 1964, A Theory of Oligopoly, Journal of Political Economy 72: 44-61.

Stiglitz, J., 1989, Imperfect Information in the Product Market, ch. 13 in R. Schmalensee \& R. Willig (eds.), Handbook of Industrial Organization, North-Holland, New York: NY.

Swedish Market Court, 2005, Verdict 2005:7, Docket no. A 2/03, Feb. 22, Stockholm: Sweden (available at http://www.marknadsdomstolen.se/avgoranden2005/Dom05-07.pdf)

Tirole, J., 1989, The Theory of Industrial Organization, MIT Press, Cambridge: MA.

Vives, X., 2002, Private Information, Strategic Behavior and Efficiency in Cournot Markets, RAND Journal of Economics 33: 361-376. 